\title{
Forecasting the volatility of EUA futures with economic policy uncertainty using the GARCH-MIDAS model
}

\author{
Jian Liu' ${ }^{1}$ Ziting Zhang ${ }^{1}$, Lizhao Yan² and Fenghua Wen ${ }^{3 *}$ (D)
}

\author{
${ }^{*}$ Correspondence: \\ mailtowfh@126.com \\ ${ }^{3}$ Business School, Central \\ South Univerdity, Changsha, \\ Hunan, People's Republic \\ of China \\ Full list of author information \\ is available at the end of the \\ article
}

\begin{abstract}
This study investigates the impact of economic policy uncertainty (EPU) on the volatility of European Union (EU) carbon futures prices and whether it has predictive power for the volatility of carbon futures prices. The GARCH-MIDAS model is applied for evaluating the impact of different EPU indexes on the price volatility of European Union Allowance (EUA) futures. We then compare the predictive power for the volatility of the two GARCH-MIDAS models based on different EPU indexes and six GARCH-type models. Our empirical results show that the GARCH-MIDAS models, which exhibit superior out-of-sample predictive ability, outperform GARCH-type models. The results also indicate that EPU has noticeable effect on the volatility of EUA futures. Specifically, the forecast accuracy of the EU EPU index is significantly higher than that of the global EPU index. Robustness checks further confirm that the EPU index (especially the EPU index of the EU) has strong predictive power for EUA futures prices. Additionally, using the volatility forecasting methods that GARCH-MIDAS models combine with the EPU index, investors can construct their portfolios to realize economic returns.
\end{abstract}

Keywords: EUA, Economic policy uncertainty, GARCH-MIDAS, Volatility forecasting, Futures

\section{Introduction}

Since the inception of the European Union Emissions Trading System (EU ETS), carbon derivatives have been traded. Moreover, futures trading is the main section of the EU ETS. Carbon futures not only provides more effective risk management tools for enterprises controlling emissions but also opportunities for investors to engage in speculative arbitrage activities. Hence, carbon futures help improve market liquidity and effectively circumvent the risk for participants (Zhou and Li 2019). Moreover, the price fluctuations of carbon futures can reflect overall market price trend (Tang et al. 2013; Milunovich and Joyeux 2010). This provides a basis for carbon market policymakers to formulate effective management policies. Owing to the relatively short development history, the risk mechanism for the EU carbon market has not yet been completed. An effective method of volatility forecasting can contribute to improving risk management capability. Meanwhile, increasing participation of financial intermediaries and international author(s) and the source, provide a link to the Creative Commons licence, and indicate if changes were made. The images or other third party material in this article are included in the article's Creative Commons licence, unless indicated otherwise in a credit line to the material. If material is not included in the article's Creative Commons licence and your intended use is not permitted by statutory regulation or exceeds the permitted use, you will need to obtain permission directly from the copyright holder. To view a copy of this licence, visit http:// creativecommons.org/licenses/by/4.0/. 
economics and politics has increased the complexity and volatility of the carbon market. For these reasons, effective measurement of carbon futures market volatility is of great significance for market participants. Therefore, predictions on EU ETS carbon futures price volatility were analyzed.

Currently, economic situations and policy adjustments have proven vital in the volatility of carbon prices (Zhu and Chevallier 2017; Kautto et al. 2012; Fan et al. 2017; Chevallier 2011). Economic and policy changes also signify uncertainty. From the perspective of the underlying logic of the relationship, the uncertainty caused by economic policy changes mainly affects the carbon futures market through the following three channels. First, since the generation and operation of the carbon futures market primarily depend on government policies, the allocation system will directly determine the supply of the carbon quota in the market. This affects the price of carbon futures (Chevallier 2009; Kanamura 2019; Mansanet-Bataller and Pardo 2009). Second, the uncertainty regarding economic policy changes will affect the production behavior and carbon emissions of regulated enterprises, which affects the demand for the carbon quota and causing price fluctuations in carbon futures. Alshubiri et al. (2020) highlight that the 2008 subprime mortgage reduced the activities of oil-relevant enterprises, and Bel and Joseph (2015) found that the economic recession caused by the subprime mortgage crisis in 2008 led to a sharp decrease in the demand for carbon quota and caused the carbon quota price to plummet. Third, economic policy uncertainty will have an impact on the energy market (Wei et al. 2017; Aloui et al. 2016; Yin 2016; Chen et al. 2020). In contrast, volatility in the energy market can affect the carbon futures market (Chevallier 2011; Mansanet-Bataller et al. 2007; Dutta 2019; Liu and Chen 2013). First, economic and policy factors influence the price of non-clean energy, which affects the production behavior of enterprises. Moreover, this further changes the carbon quota demand, leading to fluctuations in carbon futures prices. In contrast, supported by advances in clean energy technologies and environmental policies, enterprises may apply clean energy to replace non-clean energy. Moreover, energy consumption is related to carbon dioxide emissions(Khan et al. 2020). Here, carbon dioxide emissions per unit of capacity are reduced, resulting in decreased demand for carbon quotas and lower carbon price. Therefore, economic policy uncertainty has certain explanatory power for fluctuations in the carbon futures market.

The existing literature quantitatively measures economic policy uncertainty. Baker et al. (2016) proposed economic policy uncertainty (EPU) index for the major economies of the world. The EPU is based on the frequency of keywords, such as uncertainty, economic activity, and policy adjustments, found in newspaper coverage. The global EPU (GEPU) index is measured by Davis (2016), which is obtained by the GDP-weighted average of the EPU index of 20 countries accounting for two-thirds of the total global output. Since its introduction, the EPU index has been extensively applied in research. Moreover, based on our analysis of the relationship between EPU and the volatility of the carbon futures market, introducing EPU to explore its explanatory and predictive ability for the EUA futures fluctuations is appropriate.

This study adopts the GARCH mixed frequency data sampling (GARCH-MIDAS) model proposed by Engle et al. (2013), which allows data of different frequencies to be incorporated into the same model. Moreover, it decomposes the variance into long-term and short-term components, which can effectively enhance the prediction accuracy. 
Therefore, the GARCH-MIDAS model is adopted to explore the connection between EPU and EUA futures. Additionally, the GARCH-MIDAS model and GARCH-type models are compared in terms of predictive performance for EUA futures.

Our analysis of the relationship between the EU carbon futures market and economic policy uncertainty is original and can provide a new perspective for measuring the volatility of the EU carbon futures market. The main contributions of this study can be summarized as follows. First, combined with the GARCH-MIDAS model proposed by Engle et al. (2013), we add the EPU index to the EUA futures forecasting model. The empirical results confirm that the EPU has great predictive performance for the volatility of EUA futures and that GARCH-MIDAS models significantly outperform GARCH-type models in forecasting performance by using the out-of-sample test. Our analysis proves that EPU is a new and valid approach to EUA futures volatility forecasts. Second, we not only investigate the influence of GEPU on EUA futures volatility and its prediction performance but also introduce the EEPU to analyze and predict EUA futures volatility. By comparing their predictive ability, we verified that EEPU can be more effective in predicting carbon futures price volatility than GEPU. Third, by constructing a portfolio of EUA futures and risk-free EU rates, our method can produce the economic value of volatility forecasting in practical applications.

The remainder of this paper is organized as follows. "Related literature" section presents the related literature. "Model and methodology" section describes the methodology of the study. "Data and statistical description" section introduces the data and its characteristics. "Empirical analysis" section presents the empirical analysis. Finally, "Conclusions" section. concludes the paper.

\section{Related literature}

Effective measurement of carbon futures market volatility is of great significance for various participants in the EU ETS carbon futures market. Currently, economic conditions and policy adjustments have proved vital factors in the volatility of carbon prices. An increasing number of studies have explored the links between carbon prices and macroeconomic information. Chevallier (2011) highlighted that the carbon market is affected during periods of economic expansion (recession). This confirms the existence of a link between the macroeconomic conditions and carbon price. Zhu and Chevallier (2017) confirmed that a long-term co-integration relationship exists between carbon prices and drivers, such as economic activities. The connection between carbon prices and policy changes has also been explored (Kautto et al. 2012; Fan et al. 2017). Kautto et al. (2012) verified the mutual influence between climate policy and carbon emission right price through their research. Fan et al. (2017) found that the adjustment of regulatory policies in EU ETS would also affect the earnings of European Union Allowance (EUA). Combined, these studies indicate that carbon prices are strongly tied to economic situations and policy changes.

Economic and policy changes also signify uncertainty. Existing literature quantitatively measures economic policy uncertainty. Since its introduction, the EPU index has been extensively applied in research. In the stock market volatility prediction, many studies show that the EPU index has significant and positive impact on both the Chinese stock market and that of the United States (Balcilar et al. 2019; Bahmani-Oskooee and Saha 
2019; Li et al. 2019; Yu and Song 2018; Hoque and Zaidi 2019). Regarding the volatility forecast in the energy market, some studies have proved that the EPU is significantly related to the energy market price and has superior predictive effects in out-of-sample tests (Wei et al. 2017; Aloui et al. 2016; Yin 2016). Additionally, Fang et al. (2018) hold that the GEPU index has remarkable predictive ability regarding the volatility of the global gold futures market. Some scholars have also confirmed that the EPU has noteworthy impacts on markets such as virtual currencies and correlations between various markets (Fang et al. 2017, 2019). Additionally, EPU can also affect the company's decision-making behavior, such as the financial asset allocation of a company (Huang et al. 2019; Wen et al. 2019; Yan et al. 2019) and cash flow holding (Li 2019). Based on our analysis of the relationship between EPU and the volatility of the carbon futures market above, EPU may have a certain explanatory power on carbon futures price fluctuations and can be used to predict price fluctuations in the carbon market. In addition to the influence of the economic policy in the EU, the market volatility of EUA futures may also be affected by other large economic policy changes. Therefore, we introduce the EU EPU (EEPU) and GEPU index to explore the explanatory ability of EUA futures and its ability to predict long-term fluctuations, respectively.

Existing studies mainly use classic financial time-series prediction methods, such as ARCH and GARCH-type models, to forecast the price of carbon financial products (Emenogu et al. 2020; Challa et al. 2018; Dhamija et al. 2017; Byun and Cho 2013; Koop and Tole 2013; Zeitlberger and Brauneis 2016; Venmans 2015). Nevertheless, these methods cannot guarantee both long-term and short-term prediction accuracy (Lei et al. 2018). When exogenous variables of different frequencies are added, only frequency reduction can be adopted. The processing method of frequency reduction will lose effective information from the high-frequency data and may lead to a decline in the prediction accuracy. An extended form of the model can meet more research needs (Zha et al. 2020). In this case, the GARCH-MIDAS model can effectively enhance the forecast accuracy by simultaneously incorporating the data of different frequencies simultaneously. Since its introduction, many scholars have used the GARCH-MIDAS model to analyze the volatility of the stock and energy markets, and they confirmed that the model has superior predictive performance (Yu et al. 2018; Fang et al. 2017; Wei et al. 2017; Lei et al. 2018; Li et al. 2019). The GARCH-MIDAS model has become essential for research on the correlation between macroeconomic factors and market fluctuations. Similar to general financial markets, the price volatility of EUA futures has a significant GARCH effect (Byun and Cho 2013). Hence, applying the GARCH-MIDAS model to the EU carbon market is reasonable. Therefore, we use the GARCH-MIDAS model combined with EPU to analyze and predict fluctuations in EUA futures prices. The results show that the GARCH-MIDAS model exceeds the GARCH-type models relative to predictive performance. This provides new insights into modeling and forecasting carbon price volatility.

\section{Model and methodology GARCH-MIDAS model}

To explore the contribution of a monthly frequency EPU index to the long-term volatility of daily frequency EUA futures, we adopt the GARCH-MIDAS model proposed by Engle et al. (2013). Unlike GARCH-type models, the variance is decomposed into long-term 
and short-term volatility components. Short-term fluctuations remain determined by historical fluctuation information. In contrast, long-term fluctuations are characterized by low-frequency macroeconomic variables. The basic forms are as follows:

$$
\begin{aligned}
& r_{i, t}=\mu+\sqrt{l_{t} s_{i, t}} \varepsilon_{i, t}, \forall i=1, \ldots, N_{t}, \\
& \sigma_{i, t}^{2}=l_{t} s_{i, t},
\end{aligned}
$$

where $r_{i, t}$ refers to the log return of financial assets on day $i$ of month $t$, and $\mu$ is the nonconditional mean of the return sequence. The term $N_{t}$ denotes the number of days in a month. $\varepsilon_{i, t} \mid \Phi_{i-1, t} \sim N(0,1)$, given the information set $\Phi_{i-1, t}$ up to day $(i-1)$ of period $t$. The conditional variance of the daily return is divided into two components: a short-run component defined as $s_{i, t}$ and a long-run component defined as $l_{t}$ and $\sigma_{i, t}^{2}$ is defined as the total conditional variance. The short-run volatility component $s_{i, t}$ follows the traditional GARCH $(1,1)$ process as follows:

$$
s_{i, t}=(1-\alpha-\beta)+\alpha \frac{\left(r_{i-1, t}-\mu\right)^{2}}{l_{t}}+\beta s_{i-1, t},
$$

where $\alpha$ and $\beta$ are the parameters to be estimated for the ARCH and GARCH components, respectively, where $\alpha>0, \beta>0$, and $\alpha+\beta<1$. Because the growth rate of the EPU index presented by $X_{t-k}$ can have a negative value, according to Engle et al. (2013), we convert the long-term fluctuations into the logarithmic form in this study. This can be expressed as follows:

$$
\log \left(l_{t}\right)=m+\theta \sum_{k=1}^{K} \varphi_{k}\left(\omega_{1}, \omega_{2}\right) X_{t-k},
$$

where $m$ is an intercept and $\theta$ is the slope of the weighted effect of the low-frequency macroeconomic variables lagged behind the long-term volatility of financial asset returns. The term $K$ denotes the maximum lag order of smooth volatility in MIDAS filtering. The marginal effect depends on $\theta$ and $\omega$ (Conrad et al. 2014). In contrast, $\varphi_{k}\left(\omega_{1}, \omega_{2}\right)$ represents the weighting scheme of beta weights with the independent variables $\omega_{1}$ and $\omega_{2}$, which can be expressed as follows:

$$
\begin{aligned}
& \varphi_{k}\left(\omega_{1}, \omega_{2}\right)=\frac{(k / K)^{\omega_{1}-1}(1-k / K)^{\omega_{2}-1}}{\sum_{j=1}^{K}(j / K)^{\omega_{1}-1}(1-j / K)^{\omega_{2}-1}}, \\
& \varphi_{k}\left(1, \omega_{2}\right)=\frac{(1-k / K)^{\omega_{2}-1}}{\sum_{j=1}^{K}(1-j / K)^{\omega_{2}-1}},
\end{aligned}
$$

Equation 5 is the unrestrictive weighting scheme that can produce attenuated and hump weight distributions. In contrast, Eq. 6 can be obtained from Eq. 5 with a constraint of $\omega_{1}=1$. The constraint of $\omega_{1}=1$ is applied to the unrestricted weight function to obtain the restricted weight function Eq. 6 . The restricted weighting function can only generate an attenuated weight distribution, and the attenuation rate is determined 
by the parameters $\omega_{2}$. This means that the larger the value of $\omega_{2}$, the faster the decay rate, and vice versa. Both of these beta weighting functions can be applied to the estimation of the GARCH-MIDAS model. Following Conrad and Loch (2015), the restricted weight function of $\omega_{1}=1$ is selected. Equations 1,3 , 4, and 6 form a GARCH-MIDAS model based on the EPU exponential change rate. Additionally, quasi-maximum likelihood estimation (QMLE) was adopted to estimate the parameters and parameter space $\Theta=\{\mu, \alpha, \beta, m, \theta, \omega\}$.

\section{Regression-based test for the specification of one-component GARCH}

According to Conrad and Schienle (2020), there should be misspecification testing in GARCH models in the sense of an omitted multiplicative long-term component. Hence, we apply the regression-based test proposed by Conrad and Schienle (2020) as a preliminary check before estimating the GARCH-MIDAS model. The regression model is considered in logarithmic form:

$$
\begin{aligned}
& \ln \left(\overline{R V}_{t}\right)=c+w_{0} X_{0}+v_{t}, \\
& \overline{R V}_{t}=\sum_{i=1}^{M} r_{i, t}^{2} / \hat{\sigma}_{i, t}^{2},
\end{aligned}
$$

where $X_{t}$ denotes the monthly explanatory variables, $v_{t}$ meets the independent identical distribution, and $\hat{\sigma}_{i, t}^{2}$ is the estimated variance from the model under the null hypothesis of a simple GARCH. $r_{i, t}$ refers to the daily log returns. We define $\overline{R V}_{t}$ as the sum of the volatility-adjusted squared daily returns within each month. The regression-based test checks whether the $H_{0}: w_{0}=0$ that the one-component GARCH is correctly specified can be rejected when using EPU as an explanatory variable.

\section{MCS test}

To assess the predictive power of the volatility forecasts from the GARCH-MIDAS and GARCH-type models, various loss functions were used to compare the accuracies of the different models. More criteria make a more effective analysis (Kou et al. 2021). According to Hansen et al. (2011), we employ six loss functions as criteria for evaluating the prediction accuracy of various volatility models in the empirical examination. The specific definitions of these six types of loss functions are as follows:

$$
\begin{aligned}
& M A E=\frac{1}{T} \sum_{i=1}^{T}\left|\sigma_{i}^{2}-\hat{\sigma}_{i}^{2}\right|, \\
& M S E=\frac{1}{T} \sum_{i=1}^{T}\left(\sigma_{i}^{2}-\hat{\sigma}_{i}^{2}\right)^{2}, \\
& M A D=\frac{1}{T} \sum_{i=1}^{T}\left|\sigma_{i}-\hat{\sigma}_{i}\right|,
\end{aligned}
$$




$$
\begin{aligned}
& M S D=\frac{1}{T} \sum_{i=1}^{T}\left(\sigma_{i}-\hat{\sigma}_{i}\right)^{2}, \\
& \text { QLIKE }=\frac{1}{T} \sum_{i=1}^{T}\left(\log \left(\hat{\sigma}_{i}^{2}\right)+\sigma_{i}^{2} / \hat{\sigma}_{i}^{2}\right), \\
& R^{2} L O G=\frac{1}{T} \sum_{i=1}^{T}\left(\log \left(\sigma_{i}^{2} / \hat{\sigma}_{i}^{2}\right)\right)^{2},
\end{aligned}
$$

where $\hat{\sigma}_{i}^{2}$ denotes the predicted value of the variance on day $i$ obtained by the different models, and $\sigma_{i}^{2}$ is the daily actual variance. The daily frequency realized variance is a perfect proxy for the true conditional variance (Patton 2011). Nevertheless, owing to the unavailability of data, we use the square value of the daily real return to represent the daily actual fluctuation value (Wei et al. 2017). Moreover, $T$ represents the size of the out-of-sample prediction window.

However, the loss function could not distinguish whether the loss differences of the different models were statistically significant. After the loss function value is obtained, we employ the model confidence set (MCS) test proposed by Hansen et al. (2011) to compare the prediction accuracy between models. The MCS test has an advantage over the conventional test model as it does not have to set a benchmark model. Moreover, it allows for the possibility of multiple optimal models. The MCS test process was expressed as follows:

First, it sets a model collection $M_{0}$, which contains $m$ volatility forecasting models to be inspected. After calculating the loss values of the out-of-sample forecast, we write them as $L_{u, t}^{i}$ for model $u$ of the loss function $i$ (out-of-sample window $t=1, \ldots, n$ ). Therefore, for any two predictive volatility models in model collection $M_{0}$, the relative loss function values are denoted as $d_{u v, t}=L_{u, t}^{i}-L_{v, t}^{i}\left(u, v \in M_{0}\right)$. The superior object set is defined as $M^{*}$, which can be expressed as follows:

$$
M^{*} \equiv\left\{u \in M_{0}: E\left(d_{u v, t}^{i}\right) \leq 0 \text { for all } v \in M_{0}\right\},
$$

where $E\left(d_{u v, t}^{i}\right)$ represents the mathematical expectation of $d_{u v, t}$ under the specific loss function $i$. The MCS test is a series of continuous significance tests for the models of $M_{0}$, and the model that proves to be significantly inferior to the others is eliminated. The null hypothesis of the MCS test is as follows:

$$
H_{0, M}: E\left(d_{u v, t}^{i}\right) \leq 0 \text { for all } v \in M_{0}
$$

As shown above, the null hypothesis assumes that any two models have the same predictive power. The MCS test is conducted through a series of continuous significance tests wherein models of $M_{0}$ with poor predictive power are eliminated until no models are excluded from $M_{0}$. Setting the confidence level $\alpha$, if the $p$ value is larger than $\alpha$, this indicates that this model possesses superior out-of-sample predictive ability and can survive the MCS test. The larger the $p$ value of the MCS test, the higher the prediction accuracy of the corresponding model. Additionally, if the $p$ value is smaller than $\alpha$, then this 
volatility prediction model is proven to have poor out-of-sample predictive ability and will be removed from the MCS test.

Additionally, Hansen et al. (2011) recommend using semi-quadratic statistics $T_{S Q}$ and range statistics $T_{R}$ in the model assessment process. These statistics are defined as follows:

$$
\begin{aligned}
& T_{S Q}=\max _{u, v \in M_{0}} \frac{\left(\bar{d}_{u v}^{i}\right)^{2}}{\sqrt{\operatorname{var}\left(d_{u v}^{i}\right)}}, \\
& T_{R}=\max _{u, v \in M_{0}} \frac{\left|\bar{d}_{u v}^{i}\right|}{\sqrt{v a r\left(d_{u v}^{i}\right)}}, \\
& \bar{d}_{u v}^{i}=\frac{1}{n} \sum_{t=1}^{n} d_{u v}^{i},
\end{aligned}
$$

If the $p$ values of the $T_{S Q}$ and $T_{R}$ statistics are larger than the given confidence level $\alpha$, then $H_{0}$, that is, the null hypothesis, cannot be rejected. Because the asymptotic distribution of the statistics $T_{S Q}$ and $T_{R}$ depends on the "aversion parameter" their real distributions are extraordinarily complicated. However, the bootstrap method can solve this difficulty and easily obtain the statistics $T_{S Q}, T_{R}$, and the corresponding $p$ values.

\section{Data and statistical description}

The data samples used in this study were divided into two parts. One part is the daily data of the consecutive settlement price of EUA futures from the European Climate Exchange, which is the most active carbon futures trading market in the world and includes mainly EUA futures. The other is the EPU index, which represents monthly data on macroeconomic variables. As the carbon quotas of phase I of the EU ETS are allocated for free, the enterprises controlling their emissions do not participate in carbon market transactions. To ensure the adequacy and validity of the data, we use the data of phases II and III of the EU ETS. The EUA futures data cover the period from January 1, 2008, to September 30, 2019, including 3023 pieces of daily data from the WIND database. The EPU sample period spans from January 2008 to September 2019, with 141 pieces of monthly data (EPU data are available on http://www.policyuncertain ty.com). According to Fang et al. (2017) and Liu et al. (2019a), we adopt the logarithmic rate of the returns for the EUA futures settlement price to narrow the value range of the variables so the returns of the EUA futures and EPU are of the same order of magnitude. The transformed yield is expressed as $R$, and the growth rates of the EPU indexes are denoted as ${ }^{\triangle} G E P U$ and ${ }^{\triangle} E E P U$, where ${ }^{\Delta} G E P U=\left(G E P U_{t}-G E P U_{t-1}\right) / G E P U_{t-1}$, ${ }^{\triangle} E E P U=\left(E E P U_{t}-E E P U_{t-1}\right) / E E P U_{t-1}$. The summary statistics of the transformed data are presented in Table 1.

As shown in Table 1, first, the SD of the EUA futures yield is much larger than its mean. This indicates that the EUA futures price exhibits certain volatility. Second, the yield of the EUA futures is obviously to the left and turns to form a sharp peak and thick tail. In contrast, the GEPU and EEPU indexes are to the right and have sharp 
Table 1 Descriptive statistics of transformed data

\begin{tabular}{lllrrrrrr}
\hline Variables & Mean & SD & Skew & Kurt & JB & Q(5) & ADF & ARCH test \\
\hline$R$ & $0.3 e-04$ & 0.032 & -0.805 & 19.418 & $64.057^{* * *}$ & $12.477^{* *}$ & $-47.765^{* * *}$ & $0.282^{* * *}$ \\
$\triangle G E P U$ & 0.031 & 0.220 & 1.094 & 5.383 & $61.510^{* * *}$ & $9.645^{*}$ & $-4.106^{* * *}$ & $-0.051^{* *}$ \\
$\triangle E E P U$ & 0.030 & 0.233 & 1.238 & 6.578 & $111.300^{* * *}$ & $12.120^{* *}$ & $-4.524^{* * *}$ & -0.040 \\
\hline
\end{tabular}

SD, standard deviation; Skew, skewness; Kurt, kurtosis; JB, Jarque-Bera test; Ljung-Box Q test of lagged 5 order (Q(5)); ADF, augmented Dickey-Fuller unit root test. In the case of the ARCH test, the table reports the coefficient of a first-order lag $* * * * * *{ }^{*}$ Indicate significance at the $1 \%, 5 \%, 10 \%$ levels, respectively

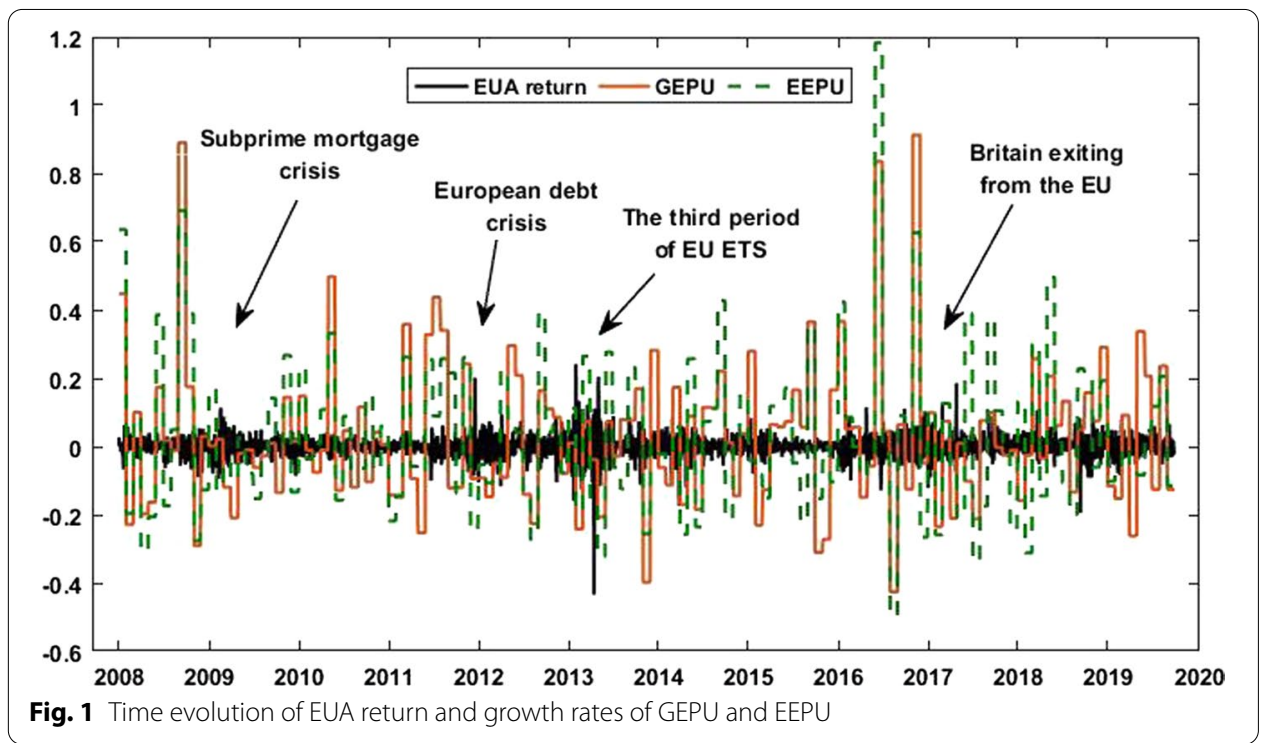

peaks. The JB test also revealed that all yield (growth rate) sequences were significantly abnormally distributed and provided evidence of autocorrelation characteristics with different degrees. Finally, all results of the ADF test support the rejection of the null hypothesis of a unit root significantly. This implies that the all-time series is stationary and can thus be modeled. Furthermore, the variation trend diagrams of the EUA yield sequence, GEPU, and EEPU volatility sequences are shown in Fig. 1.

As displayed in Fig. 1, the four major events throughout the sample period result in significant fluctuations and an agglomeration effect of carbon futures prices. For instance, affected by the subprime mortgage crisis in 2008, companies were selling their excess carbon allowances, leading to a glut of carbon allowances in the market and plummeting of carbon prices. During the European debt crisis in 2011, GEPU and EEPU fluctuated drastically. The European economy was in recession, thus affecting carbon prices. EUA futures prices fluctuated sharply in 2013 as the EU ETS entered phase III because of the oversupply of carbon quotas in the first few months and the subsequent rejection of a "volume auction" by the European parliament. Subsequently, structural reforms in the EU ETS led to an increase in prices. Additionally, the Brexit referendum in 2016, together with the presidential election of the USA and the interest rate of Fed raised, brought higher uncertainty to the global economy and increased volatility in EUA futures prices. Both the EPU index and EUA futures prices 
fluctuated sharply during these four events. The price fluctuations of the EU carbon futures market can be considered closely related to economy and policy uncertainty.

\section{Empirical analysis}

In this section, we first conduct a regression-based test to check whether a simple GARCH is misspecified in the sense of an omitted long-term component. Second, we analyze the results of the parameter estimation of the two GARCH-MIDAS models based on different EPU indexes for the entire sample period. The data were then divided into two parts for the out-of-sample prediction of the rolling window.

\section{Regression-based test}

As Table 2 shows, the results of parameter $w_{0}$ are positive at the $1 \%$ significance level, indicating the connection between EPU and monthly realized volatility of EUA futures. Additionally, the results indicate that the two models are significant under the F-statistic test. Moreover, this means that in the null hypothesis, the one-component GARCH is correctly specified can be rejected. A significant relationship is found between the EPU index and the log of the volatility-adjusted realized variance of EUA futures. Therefore, this preliminary check can provide evidence that we can adopt the GARCH-MIDAS model to forecast EUA futures using the EPU index.

\section{Model estimation}

To examine the applicability of the GARCH-MIDAS model for the prediction of EUA futures volatility and analyze the influence of different EPU indexes, we perform a parameter estimation of the entire sample in this subsection. According to Conrad et al. (2015), the maximum lag order $K$ of the model is determined using the information criterion. However, owing to the existence of a flexible weight function, a lag order that is as large as possible can be selected. After calculating the beta function with different lag orders, we choose 24 to be $K$. Hence, the lag time range of the influence of the EPU index on the volatility of the carbon futures market is 24 months. The parameter estimation results are presented in Table 3. First, the parameters $\mu, \alpha$, and $\beta$ are significant, with the sum of $\alpha$ and $\beta$ being close to 1 . This indicates that the short-term volatility components of the EUA futures price yield show a noteworthy GARCH $(1,1)$ effect. Second, both the estimated results of $\theta$ of these two models are positive at the $1 \%$ level, with the effect of GEPU being larger than that of EEPU. This implies that GEPU and EEPU are positively correlated with the long-term volatility components of the EUA futures yield and produce a positive effect on the EUA futures price. Basically, a larger growth

Table 2 Results of regression-based test

\begin{tabular}{llll}
\hline$X_{t}$ & $c$ & $w_{0}$ & F-statistic \\
\hline$\triangle_{\text {GEPU }}$ & $2.947^{* * *}$ & $0.532^{* * *}$ & $9.71^{* * *}$ \\
& $(0.000)$ & $(0.002)$ & $(0.002)$ \\
$\triangle_{\text {EEPU }}$ & $2.945^{* * *}$ & $0.561^{* * *}$ & $12.890^{* * *}$ \\
& $(0.000)$ & $(0.000)$ & $(0.001)$ \\
\hline
\end{tabular}

$* * * * * *$ Indicate significance at the $1 \%, 5 \%, 10 \%$ levels, respectively. The values in parentheses are the $p$ values 
Table 3 Full-sample estimates of GARCH-MIDAS models

\begin{tabular}{|c|c|c|c|c|c|c|c|c|}
\hline Variables & $\mu$ & $\alpha$ & $\beta$ & $\mathrm{m}$ & $\theta$ & $\omega$ & LLF & AIC \\
\hline \multirow[t]{2}{*}{$\triangle_{G E P U}$} & $1.002 \mathrm{E}-03^{* *}$ & $0.124^{* * *}$ & $0.865^{* * *}$ & $-6.990^{* * *}$ & $16.978^{* * *}$ & $1.117^{* * *}$ & 5477.820 & $-10,944$ \\
\hline & $(0.024)$ & $(0.000)$ & $(0.000)$ & $(0.000)$ & $(0.000)$ & $(0.000)$ & & \\
\hline \multirow[t]{2}{*}{$\triangle E E P U$} & $0.987 e-03^{* *}$ & $0.120^{* * *}$ & $0.870^{* * *}$ & $-6.937^{* * *}$ & $13.634^{* * *}$ & $1.092^{* * *}$ & 5475.020 & $-10,938$ \\
\hline & $(0.026)$ & $(0.000)$ & $(0.000)$ & $(0.000)$ & $(0.000)$ & $(0.000)$ & & \\
\hline
\end{tabular}

***,**, Indicate significance at the $1 \%, 5 \%, 10 \%$ levels, respectively. The LLF is the log-likelihood function. The $p$ values are shown in parentheses below the corresponding parameter estimates
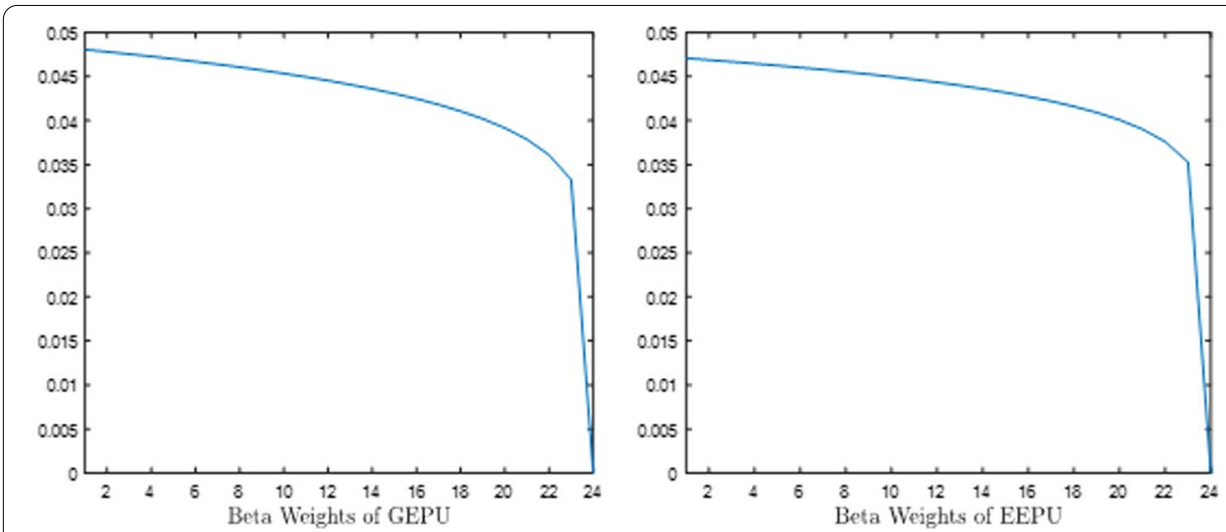

Fig. 2 Distributions of beta weights function

rate of the EPU index leads to higher volatility in the EUA futures price. Overall, the GEPU and EEPU indexes have significant and positive effects on the long-term components of the EU carbon futures market volatility. When economic policy uncertainty increases, the EU carbon market becomes more volatile. Once the economic cycle of a recession is entered, the economic activity of factories will be greatly reduced. Therefore, the demand for quotas will be greatly reduced, resulting in drastic fluctuations in carbon prices in the carbon market. Market participants in the EU carbon market should be vigilant during periods of high economic policy uncertainty.

Based on the estimation results above, the distributions of the beta weight function of the two modes are drawn. In Fig. 2, both weight functions show a decreasing distribution, indicating that the closer the volatilities of GEPU and EEPU are to the current time, the more the variables influence the EUA futures price volatility. As the parameter $\omega$ estimated by the $\triangle G E P U$ model is larger than that of the GM- $\triangle E E P U$, the rate of decay of the former is faster than that of the latter. Additionally, Fig. 3 presents the EUA futures price volatility and long-term volatility trend charts. The green dotted line is the actual daily volatility variance of EUA futures. In contrast, the blue solid line is the long-term volatility variance of the obtained model. A certain connection between long-term fluctuations and total fluctuations of EUA futures prices driven by different EPU indexes can be observed. The total volatility trend is also in line with the economic conditions of the EU and the world. Specifically, the subprime crisis in 2011 led to an economic recession, and EPU indexes rose rapidly during the same period. The EU carbon market was also deeply affected by the crisis, and the EUA futures price volatility 

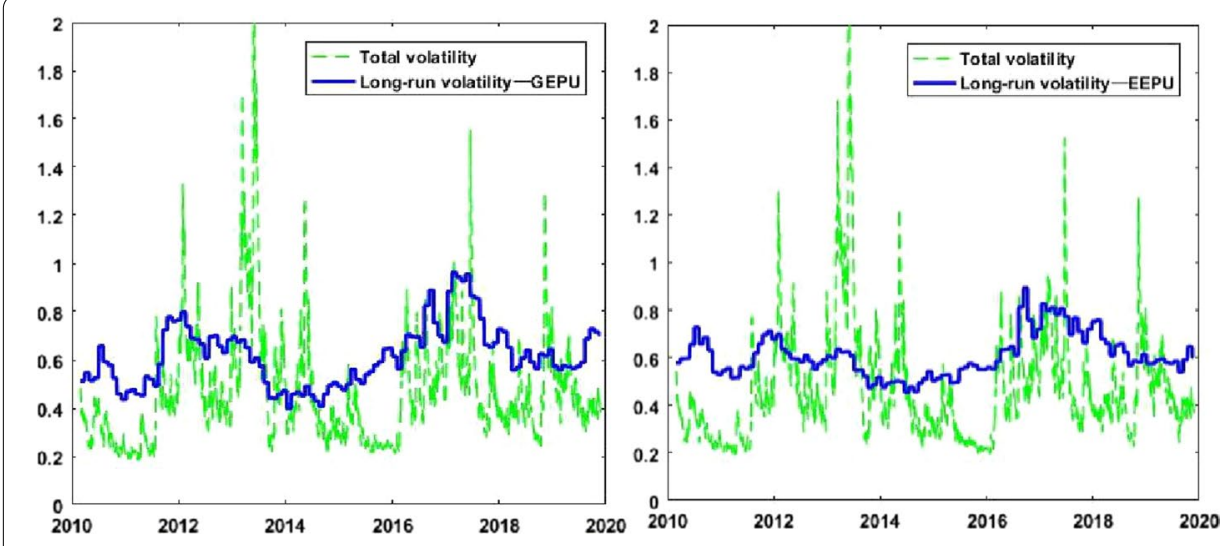

Fig. 3 Trend of total volatility and long-term volatility by the two GARCH-MIDAS models

and long-term volatility rose sharply. In the recovery stage of the subprime crisis, the EPU index fell, reducing the long-term volatility of EUA futures, and the decline in the instability of the EU carbon market also reduced the EUA futures' total volatility. During phase III of the EU ETS in 2013 and the UK referendum in 2016, long-term fluctuations and total fluctuations also followed the above trend. However, the EPU index that can affect EUA futures cannot be judged based on the estimated results only. We focus on exploring which EPU index can be more useful in forecasting the daily volatility of EUA futures prices. In the next section, we evaluate the predictive performances of these two EPU indexes and discuss the relationships between the two GARCH-MIDAS models and EUA futures volatility.

\section{Evaluation of the forecast performance}

The estimated results of the samples change with time. Market participants are more concerned about the out-of-sample predictive ability of the model and the indicator that can most accurately predict future fluctuations than the estimated results in a sample (Wang et al. 2016). In the next step, we empirically test the out-of-sample predictive power of the EPU index. The data are divided into two subgroups: in-sample data for estimating the parameters and out-of-sample data for forecasting volatility. Specifically, in-sample data of 2623 trading days and out-of-sample data of the last 400 trading days were included. We adopt the step forward rolling forecast method, which means that the first estimate uses the data of the first 2623 days to forecast the volatility of the following day. For the second estimate, we eliminated the first data and combined the recent data to keep the parameter estimate sample sizes fixed. Each estimate yields an out-of-sample forecast value. Using a rolling window, two GARCH-MIDAS models and six GARCHtype models were predicted to obtain 400 out-of-sample predicted values. Additionally, we employ the MCS test to determine whether the loss differences of the different models are statistically significant. For the control parameters of the MCS test, we set $K=2$ (block bootstrap length) and simulation times $B=10,000$. Meanwhile, the confidence level $\alpha$ was set to 0.1 (Hansen et al. 2011; Wang et al. 2016; Zhang et al. 2019). If the $p$ value is larger than 0.1, the model can survive in the MCS test. Otherwise, the model 
is removed. The larger the $p$ value, the better is the predictive power of the model. The MCS test results are listed in Table 4.

Table 4 reports the MCS test results of all the models. The two models based on ${ }^{\triangle} G E P U$ and ${ }^{\triangle} E E P U$ passed the MCS test with the GM- ${ }^{\Delta} E E P U$, which obtains the highest forecasting accuracy in general. In contrast, few GARCH-type models survived in the MCS test. Essentially, the GARCH-MIDAS model with EPU index has better prediction performance relative to EUA futures volatility than other models. The results mean that, the GARCH-MIDAS model incorporated EPU indices that can predict the EUA futures price fluctuations more accurately in contrast to the GARCH-type models. Our results further confirmed that EPU contains useful information in EUA futures volatility. Participants should consider EPU when making investments in the EU carbon market. Additionally, by comparing the two GARCH-MIDAS models based on different EPU indexes, the $p$ values of the two mixing models under different loss functions are different. Overall, for this out-of-sample prediction window, EEPU contains more useful information than GEPU. On the one hand, the EU ETS is an emerging market for more than a decade with imperfect market mechanism. This makes the carbon market more vulnerable to economic uncertainty within the economy in which it operates. On the other hand, the establishment and operation of the EU ETS was accompanied by the adjustment of corresponding policies by the government. The economic policy uncertainty in EU can cause EUA futures price fluctuations more easily than the economic policy changes in other economies. Therefore, most of the volatility in carbon markets can be explained by EEPU, and the effect of EEPU on the predictive ability of the EUA futures price is stronger.

\section{Robustness checks}

\section{EUA futures of weekly rate of return}

In this section, we use the weekly rate of return for alternative robustness testing (Liu et al. 2019b; Kang et al. 2019). Weekly yield is denoted by $R_{m}=\ln \left(p_{1, w}\right)-\ln \left(p_{5, w}\right)$ using the data from the first and last days of a week. When the other conditions remain the same, we choose window sizes of 80 weeks, which means 400 trading days. The results of the MCS tests are presented in Table 5. Two of the GARCH-MIDAS models passed the MCS test, and the GM- ${ }^{\triangle} G E P U$ obtained the highest forecasting accuracy in all models.

Table 4 MCS test results of the model (400-day out-of-sample prediction window)

\begin{tabular}{|c|c|c|c|c|c|c|c|c|c|c|c|c|}
\hline \multirow[t]{2}{*}{ Model } & \multicolumn{2}{|l|}{ MAE } & \multicolumn{2}{|l|}{ MSE } & \multicolumn{2}{|l|}{ MAD } & \multicolumn{2}{|l|}{ MSD } & \multicolumn{2}{|l|}{$R^{2}$ LOG } & \multicolumn{2}{|l|}{ QLIKE } \\
\hline & $T_{R}$ & $T_{S Q}$ & $T_{R}$ & $T_{S Q}$ & $T_{R}$ & $T_{S Q}$ & $T_{R}$ & $T_{S Q}$ & $T_{R}$ & $T_{S Q}$ & $T_{R}$ & $T_{S Q}$ \\
\hline $\mathrm{GM}-\triangle \mathrm{GEPU}$ & 0.064 & 0.053 & 0.525 & 0.628 & 0.027 & 0.019 & 0.175 & 0.175 & 0.153 & 0.206 & 0.335 & 0.264 \\
\hline $\mathrm{GM}-\triangle E E P U$ & 1.000 & 1.000 & 0.978 & 0.978 & 1.000 & 1.000 & 1.000 & 1.000 & 1.000 & 1.000 & 1.000 & 1.000 \\
\hline GARCH & 0.001 & 0.006 & 0.221 & 0.118 & 0.000 & 0.000 & 0.003 & 0.005 & 0.000 & 0.000 & 0.335 & 0.264 \\
\hline GJRGARCH & 0.003 & 0.009 & 0.105 & 0.060 & 0.001 & 0.000 & 0.003 & 0.004 & 0.000 & 0.002 & 0.319 & 0.233 \\
\hline NAGERCH & 0.031 & 0.029 & 0.221 & 0.211 & 0.027 & 0.019 & 0.094 & 0.050 & 0.576 & 0.576 & 0.319 & 0.233 \\
\hline $\mathrm{NGARCH}$ & 0.003 & 0.013 & 0.525 & 0.628 & 0.000 & 0.000 & 0.003 & 0.004 & 0.000 & 0.000 & 0.319 & 0.233 \\
\hline EGARCH & 0.064 & 0.053 & 1.000 & 1.000 & 0.004 & 0.003 & 0.094 & 0.050 & 0.000 & 0.000 & 0.113 & 0.123 \\
\hline IGARCH & 0.000 & 0.002 & 0.221 & 0.138 & 0.000 & 0.000 & 0.000 & 0.002 & 0.000 & 0.000 & 0.335 & 0.264 \\
\hline
\end{tabular}

The bold numbers represent the models with $p$ value greater than 0.1 
Table 5 MCS test results of the model (80-week out-of-sample prediction window of weekly yield)

\begin{tabular}{|c|c|c|c|c|c|c|c|c|c|c|c|c|}
\hline \multirow[t]{2}{*}{ Model } & \multicolumn{2}{|l|}{ MAE } & \multicolumn{2}{|l|}{ MSE } & \multicolumn{2}{|l|}{ MAD } & \multicolumn{2}{|l|}{ MSD } & \multicolumn{2}{|l|}{$R^{2}$ LOG } & \multicolumn{2}{|l|}{ QLIKE } \\
\hline & $T_{R}$ & $T_{S Q}$ & $T_{R}$ & $T_{S Q}$ & $T_{R}$ & $T_{S Q}$ & $T_{R}$ & $T_{S Q}$ & $\overline{T_{R}}$ & $T_{S Q}$ & $T_{R}$ & $T_{S Q}$ \\
\hline $\mathrm{GM}-\triangle \mathrm{GEPU}$ & 1.000 & 1.000 & 1.000 & 1.000 & 1.000 & 1.000 & 1.000 & 1.000 & 1.000 & 1.000 & 1.000 & 1.000 \\
\hline$G M-\triangle E E P U$ & 0.609 & 0.682 & 0.720 & 0.838 & 0.351 & 0.325 & 0.423 & 0.409 & 0.922 & 0.935 & 0.794 & 0.790 \\
\hline GARCH & 0.126 & 0.300 & 0.128 & 0.398 & 0.351 & 0.325 & 0.082 & 0.146 & 0.019 & 0.199 & 0.350 & 0.495 \\
\hline GJRGARCH & 0.675 & 0.682 & 0.872 & 0.848 & 0.582 & 0.473 & 0.436 & 0.460 & 0.922 & 0.935 & 0.794 & 0.790 \\
\hline NAGARCH & 0.609 & 0.682 & 0.720 & 0.838 & 0.351 & 0.325 & 0.423 & 0.409 & 0.922 & 0.935 & 0.350 & 0.495 \\
\hline $\mathrm{NGARCH}$ & 0.093 & 0.217 & 0.079 & 0.187 & 0.582 & 0.458 & 0.082 & 0.110 & 0.019 & 0.042 & 0.350 & 0.410 \\
\hline EGARCH & 0.700 & 0.700 & 0.872 & 0.848 & 0.886 & 0.886 & 0.464 & 0.464 & 0.922 & 0.935 & 0.597 & 0.695 \\
\hline IGARCH & 0.005 & 0.029 & 0.004 & 0.024 & 0.351 & 0.325 & 0.032 & 0.036 & 0.019 & 0.001 & 0.350 & 0.328 \\
\hline
\end{tabular}

The bold numbers represent the models with $p$ value greater than 0.1

Table 6 MCS test results of the model (using the logarithmic growth rate of EPU)

\begin{tabular}{|c|c|c|c|c|c|c|c|c|c|c|c|c|}
\hline \multirow[t]{2}{*}{ Model } & \multicolumn{2}{|l|}{ MAE } & \multicolumn{2}{|l|}{ MSE } & \multicolumn{2}{|l|}{ MAD } & \multicolumn{2}{|l|}{ MSD } & \multicolumn{2}{|c|}{$R^{2}$ LOG } & \multicolumn{2}{|l|}{ QLIKE } \\
\hline & $T_{R}$ & $T_{S Q}$ & $T_{R}$ & $T_{S Q}$ & $T_{R}$ & $T_{S Q}$ & $T_{R}$ & $T_{S Q}$ & $T_{R}$ & $T_{S Q}$ & $T_{R}$ & $T_{S Q}$ \\
\hline$G M-* G E P U$ & 0.059 & 0.059 & 0.778 & 0.778 & 0.024 & 0.024 & 0.198 & 0.198 & 0.038 & 0.038 & 0.881 & 0.957 \\
\hline GM-*EEPU & 1.000 & 1.000 & 1.000 & 1.000 & 1.000 & 1.000 & 1.000 & 1.000 & 1.000 & 1.000 & 0.881 & 0.957 \\
\hline GARCH & 0.000 & 0.000 & 0.110 & 0.159 & 0.000 & 0.000 & 0.000 & 0.000 & 0.000 & 0.000 & 1.000 & 1.000 \\
\hline GJRGARCH & 0.000 & 0.000 & 0.368 & 0.295 & 0.000 & 0.000 & 0.000 & 0.002 & 0.000 & 0.000 & 0.881 & 0.957 \\
\hline NAGERCH & 0.008 & 0.007 & 0.566 & 0.585 & 0.003 & 0.003 & 0.020 & 0.028 & 0.001 & 0.001 & 0.881 & 0.957 \\
\hline VGARCH & 0.000 & 0.000 & 0.157 & 0.188 & 0.000 & 0.000 & 0.000 & 0.000 & 0.000 & 0.000 & 0.881 & 0.957 \\
\hline GARCH & 0.000 & 0.000 & 0.094 & 0.087 & 0.000 & 0.000 & 0.000 & 0.000 & 0.000 & 0.000 & 0.881 & 0.900 \\
\hline ARCH & 0.000 & 0.000 & 0.094 & 0.097 & 0.000 & 0.000 & 0.000 & 0.000 & 0.000 & 0.000 & 0.881 & 0.957 \\
\hline
\end{tabular}

The bold numbers represent the models with $p$ value greater than 0.1

Additionally, few GARCH-type models survived the MCS test. The empirical results confirmed that the predictive power of GARCH-MIDAS with the EPU index is significantly better than that of the six GARCH-type models. This further suggests that, compared with the GARCH-type models, the GARCH-MIDAS model with the EPU index helps enhance the predictive power of EUA futures prices. Basically, the EPU index contains more useful information regarding the EU carbon futures price volatility than the GEPU index, which demonstrates the robustness of the above conclusion.

\section{EPU of logarithmic growth rate}

According to Fang et al. (2019), the EPU data are transformed to logarithm growth rates to measure the out-of-sample predictive ability. The new variables are expressed as ${ }^{*} G E P U$ and ${ }^{*} E E P U$, where ${ }^{*} G E P U=\ln \left(G E P U_{t}\right)-\ln \left(G E P U_{t-1}\right)$, ${ }^{*} E E P U=\ln \left(E E P U_{t}\right)-\ln \left(E E P U_{t-1}\right)$. Table 6 reports the MCS results, and we find that only the GM- ${ }^{*} E E P U$ model survived the MCS test under all loss functions. The GM-*GEPU model was removed with respect to the MAD and MAE loss functions. However, they outperformed GARCH-type models in most cases. Additionally, all the GARCH-type models survive only under the QLIKE loss function with the $T_{R}$ and $T_{S Q}$ test statistics, and they are eliminated in most cases. This provides strong evidence that 
the GARCH-MIDAS models can outperform GARCH-type models, showing the vital role of EPU in enhancing the predictive performance for EUA futures. Additionally, the EEPU can provide more useful information than GEPU, showing its superior ability to predict EUA futures price fluctuations.

\section{Portfolio returns}

As EPU indices can be helpful in forecasting the volatility of EUA futures, using the prediction results to effectively allocate assets is still significant for investors. In this section, we further explore the economic significance of these models. We consider a mean-variance utility investor who allocates his or her assets based on the forecasting volatility between the EUA futures and risk-free assets. Here, we adopt the forecast values of the 400-day out-of-sample window, and the risk-free asset is presented by EONIA rates, a bank overnight rate of the Eurozone [https://sdw.ecb.europa.eu/]. The portfolio returns of a given time $t$ can be represented as follows:

$$
R_{p, t}=\omega_{t} r_{\text {eua }, t}+\left(1-\omega_{t}\right) r_{f, t}=\omega_{t} r_{\text {eua }, t}^{*}+r_{f, t}
$$

where $\omega_{t}$ is the weight of the portfolio of EUA futures. $r_{\text {eua }}$ and $r_{f}$ are the yields of the EUA futures and EONIA rates, respectively. $r_{\text {eua,t }}^{*}$ is the excess return, which equals $r_{\text {eua,t }}$ minus $r_{f}$. Following Campbell and Thompson (2008) and Zhang et al. (2018), a meanvariance utility investor, the utility function of an investment strategy is equal to:

$$
U\left(R_{p, t}\right)=E_{t}\left(R_{p, t}\right)-0.5 \gamma \operatorname{Var}\left(R_{p, t}\right)
$$

where $\gamma$ denotes the risk-aversion coefficient. When the value of $\gamma$ increases, the risk asset of EUA futures is assigned a lower optimal weight in the portfolio. According to Wang et al. (2016), we set values 3, 6, and 9 for $\gamma$ for a robustness check. By maximizing the utility function, the optimal portfolio weight can be obtained. It can be expressed as follows:

$$
\omega_{t}^{*}=\frac{1}{\gamma} \frac{\widehat{r}_{e u a, t+1}^{*}}{\widehat{\sigma}_{\text {eua }, t+1}^{*}}
$$

where $\widehat{r}_{\text {eua,t+1 }}^{*}$ is the rolling window forecast of the EUA futures excess return on day $t+1$ and is the corresponding estimate of the excess return volatility on day $t+1$. To preclude short sales and prevent more than $50 \%$ leverage, we restrict $\omega_{t}$ to lie between 0 and 1.5 (Wang et al. 2016). We use the certainty equivalent return (CER) to evaluate portfolio performance.

$$
C E R=\widehat{\mu}_{p}-\frac{\gamma}{2} \widehat{\sigma}_{p}^{2}
$$

where $\widehat{\mu}_{p}$ and $\widehat{\sigma}_{p}^{2}$ are the mean and variance of the portfolio during the out-of-sample period, respectively.

Table 7 reports the daily mean excess returns and CER for the eight models over the 400-day out-of-sample period. The GARCH-MIDAS models can generate substantially higher economic returns for the mean-variance investor in contrast to the GARCH-type models. Among all models, the GM- ${ }^{\Delta} E E P U$ model obtains the highest excess returns, 
Table 7 Portfolio performance over the 400-day out-of-sample period

\begin{tabular}{|c|c|c|c|c|c|c|}
\hline \multirow[t]{2}{*}{ Model } & \multicolumn{2}{|l|}{$\gamma=3$} & \multicolumn{2}{|l|}{$\gamma=6$} & \multicolumn{2}{|l|}{$\gamma=9$} \\
\hline & $R$ & CER & $\mathrm{R}$ & CER & $R$ & CER \\
\hline $\mathrm{GM}^{-}{ }^{\Delta} \mathrm{GEPU}$ & $0.132^{*}$ & 0.095 & 0.065 & 0.045 & 0.043 & 0.029 \\
\hline $\mathrm{GM}^{-}{ }^{\Delta} \mathrm{EEPU}$ & $0.147^{*}$ & 0.111 & $0.082 * *$ & 0.062 & $0.057^{* *}$ & 0.043 \\
\hline GARCH & 0.098 & 0.076 & 0.048 & 0.037 & 0.032 & 0.025 \\
\hline GJRGARCH & 0.064 & 0.050 & 0.031 & 0.024 & 0.021 & 0.016 \\
\hline NAGARCH & 0.046 & 0.036 & 0.023 & 0.018 & 0.015 & 0.011 \\
\hline NGARCH & $0.105^{*}$ & 0.081 & 0.052 & 0.040 & 0.034 & 0.026 \\
\hline EGARCH & 0.093 & 0.071 & 0.046 & 0.035 & 0.030 & 0.023 \\
\hline IGARCH & 0.098 & 0.076 & 0.049 & 0.037 & 0.032 & 0.024 \\
\hline
\end{tabular}

$\mathrm{R}$ is the mean excess returns and CER denotes the certainty equivalent returns. ${ }^{* *}, *$ indicate significance at the $5 \%$ and $10 \%$ levels, respectively, under the t-statistics test. All values were based on days multiplied by 100 . Bold numbers represent the largest values for each column

confirming the prediction results above. For larger values of $\gamma$, the mean excess return from GM- ${ }^{\triangle} E E P U$ becomes lower but still statistically significant. The results imply that the GARCH-MIDAS model with EPU can not only obtain higher forecasts but also have better performance in portfolio.

\section{Conclusions}

In this study, the GARCH-MIDAS model is adopted to investigate the forecasting performance of EPU on EUA futures price volatility. Some noteworthy conclusions were drawn. First, both GEPU and EEPU indexes have remarkable and positive effects on the long-term components of the EU carbon futures market volatility. The results indicate that when EPU increases, the EU carbon market will become more volatile. Policymakers, market participants, and especially institutional investors in EU carbon market should be vigilant during the period of high economics policy uncertainty. Second, the GARCH-MIDAS models with variable EPU are superior to the GARCH-type models, and the former can more accurately predict EUA futures price fluctuations. By adding the EPU indices, the forecast performance of EUA futures increases. Additionally, the prediction performance of the GM- $\triangle E E P U$ for EUA futures prices is markedly stronger than that of the GM- $\triangle$ GEPU. The EU ETS is a burgeoning market for more than a decade with imperfect market mechanisms. This makes the carbon market more vulnerable to economic uncertainty within the economy wherein it operates. Therefore, in the current phase, emphasizing the EU of EPU when considering the volatility of EUA futures is necessary. The robustness checks further confirm that the EPU index (especially the EPU index of the EU) has strong predictive power for EUA futures prices, and by constructing a portfolio of EUA futures and risk-free EU rates, the forecast method using EPU indices can produce economic gains for investors in practical applications.

The EU ETS has a high degree of marketization, and the market mechanism tends to become increasingly perfect. However, the higher the degree of marketization, the more sensitive the financial market to economic policy uncertainty (Wang et al. 2014). Hence, we adopt the EPU index to predict EU carbon market fluctuations and confirm its accurate predictive ability. On the one hand, our work is of great value in application. The EPU index offers an effective method for market participants to 
manage the risk of price fluctuations. Through the EPU index, investors can construct corresponding asset portfolios or design hedge strategies. When the EPU index fluctuates sharply, the EU carbon futures market will also experience large fluctuations. By determining whether the uncertainty of economic policies brings positive or negative news, investors can choose to short or long futures markets. Thus, they are more likely to reduce volatility because of the unstable carbon market. Additionally, enhancing the ability of the government to correct the implementation of carbon management strategies. During periods of heightened uncertainty, policymakers can formulate corresponding environmentally oriented policies and regulations to intervene in the carbon futures market. They are apt to avoid excessive fluctuations in price fluctuations caused by increased economic uncertainty by reducing the supply of carbon. Additionally, policymakers must strive to maintain the continuity and stability of policies in the EU carbon market and reduce the uncertainty of economic policies to achieve the long-term goal of promoting the healthy and orderly development of the EU carbon market. On the other hand, this study has great theoretical significance, as it is an effective complement to existing research on carbon market volatility. Our analysis of the relationship between the EU carbon futures market and EPU is original and may provide a relatively new perspective to measure the volatility of the EU carbon market. Meanwhile, this study could be used as a reference in other carbon market volatility studies.

\begin{abstract}
Abbreviations
EU: European Union; EU ETS: EU emission trading scheme; EPU: economic policy uncertainty; GEPU: Global EPU; EEPU: EU EPU; GARCH-MIDAS: Generalized AutoRegressive conditional heteroskedasticity mixed data sampling; EUA: European Union Allowance; MCS: Model confidence set; ARCH: Autoregressive conditional heteroskedasticity; GJRGARCH: GlostenJagannathan-Runkle GARCH; NAGARCH: Nonlinear asymmetric GARCH; IGARCH: Integrated GARCH; NGARCH: nonlinear GARCH; EGARCH: Exponential GARCH; MAE: Mean absolute error; MAD: Mean absolute deviation; MSE: Mean square error; MSD: Mean square deviation; QLIKE: Quasi-maximum likelihood loss function error; R ${ }^{2}$ LOG: Logarithmic likelihood loss function; CER: Certainty equivalent return; QMLE: Quasi-maximum likelihood estimation.
\end{abstract}

Acknowledgements

The authors thank the reviewers of this manuscript.

Authors' contributions

$J$ conducted the project, checked the initial, first and second revised versions of the paper and approved the final version. ZZ wrote the paper and revised it. LY checked the third revised versions of the paper and approved the final version. FW conducted the related calculations. All authors read and approved the final manuscript.

\title{
Funding
}

This research was supported by the National Natural Science Foundation of China (Nos. 71871030, 72131011) and the Open Fund Project of Key Research Institute of Philosophies and Social Sciences in Hunan University of China (No. 20FEFMZ1).

\section{Availability of data and materials}

The EUA data that supports the findings of this study are available from the WIND database, but restrictions apply to the availability of these data, because it is not publicly available. The EPU index data are available from http://www. policyuncertainty.com. The data on EONIA rates are available at https://sdw.ecb.europa.eu/.

\section{Declarations}

\section{Competing interests}

The authors declare that they have no competing interests.

\section{Author details}

${ }^{1}$ School of Economics and Management, Changsha University of Science and Technology, Changsha, Hunan, People's Republic of China. ${ }^{2}$ School of Business, Hunan Normal University, Changsha, Hunan, People's Republic of China. ${ }^{3}$ Business School, Central South Univerdity, Changsha, Hunan, People's Republic of China. 
Received: 19 March 2020 Accepted: 2 September 2021

Published online: 01 October 2021

\section{References}

Aloui R, Gupta R, Miller SM (2016) Uncertainty and crude oil returns. Energy Econ 55:92-100. https://doi.org/10.1016/j. eneco.2016.01.012

Alshubiri FN, Tawfik OI, Jamil SA (2020) Impact of petroleum and non-petroleum indices on financial development in Oman. Financ Innov 6(1):1-22

Bahmani-Oskooee M, Saha S (2019) On the effects of policy uncertainty on stock prices: an asymmetric analysis. Quant Financ Econ 3:412-424. https://doi.org/10.3934/QFE.2019.2.412

Baker SR, Bloom N, Davis SJ (2016) Measuring economic policy uncertainty. Q J Econ 131(4):1593-1636. https://doi.org/ 10.1093/qje/qjw024

Balcilar M, Gupta R, Kim WJ, Kyei C (2019) The role of economic policy uncertainties in predicting stock returns and their volatility for Hong Kong, Malaysia and South Korea. Int Rev Econ Finance 59:150-163. https://doi.org/10.1016/j.iref. 2018.08.016

Bel G, Joseph S (2015) Emission abatement: untangling the impacts of the eu ets and the economic crisis. Energy Econ 49:531-539. https://doi.org/10.1016/j.eneco.2015.03.014

Bj T, Shen C, Gao C (2013) The efficiency analysis of the European co2 futures market. Appl Energy 112:1544-1547. https://doi.org/10.1016/j.apenergy.2013.02.017

Byun SJ, Cho H (2013) Forecasting carbon futures volatility using Garch models with energy volatilities. Energy Econ 40:207-221. https://doi.org/10.1016/j.eneco.2013.06.017

Campbell JY, Thompson SB (2008) Predicting excess stock returns out of sample: Can anything beat the historical average? Rev Financ Stud 21(4):1509-1531

Challa ML, Malepati V, Kolusu SNR (2018) Forecasting risk using auto regressive integrated moving average approach: an evidence from s\&p bse sensex. Financ Innov 4(1):24. https://doi.org/10.1186/s40854-018-0107-z

Chen X, Li Y, Xiao J, Wen F (2020) Oil shocks, competition, and corporate investment: evidence from china. Energy Econ 104819

Chevallier J (2009) Carbon futures and macroeconomic risk factors: a view from the eu ets. Energy Econ 31(4):614-625. https://doi.org/10.1016/j.eneco.2009.02.008

Chevallier J (2011) A model of carbon price interactions with macroeconomic and energy dynamics. Energy Econ 33(6):1295-1312. https://doi.org/10.1016/j.eneco.2011.07.012

Conrad C, Loch K (2015) Anticipating long-term stock market volatility. J Appl Econom 30(7):1090-1114. https://doi.org/ $10.1002 /$ jae. 2404

Conrad C, Schienle M (2020) Testing for an omitted multiplicative long-term component in Garch models. J Bus Econ Stat 38(2):229-242

Conrad C, Loch K, Rittler D (2014) On the macroeconomic determinants of long-term volatilities and correlations in us stock and crude oil markets. J Empir Financ 29:26-40

Davis SJ (2016) An index of global economic policy uncertainty. Technical report, National Bureau of Economic Research

Dhamija AK, Yadav SS, Jain P (2017) Forecasting volatility of carbon under eu ets: a multi-phase study. Environ Econ Policy Stud 19(2):299-335. https://doi.org/10.1007/s10018-016-0155-4

Dutta A (2019) Impact of carbon emission trading on the European union biodiesel feedstock market. Biomass Bioenerg 128:105328. https://doi.org/10.1016/j.biombioe.2019.105328

Emenogu NG, Adenomon MO, Nweze NO (2020) On the volatility of daily stock returns of total Nigeria plc: evidence from Garch models, value-at-risk and backtesting. Financ Innov 6(1):1-25. https://doi.org/10.1186/s40854-020-00178-1

Engle RF, Ghysels E, Sohn B (2013) Stock market volatility and macroeconomic fundamentals. Rev Econ Stat 95(3):776797. https://doi.org/10.1162/REST_a_00300

Fan Y, Jia JJ, Wang X, Xu JH (2017) What policy adjustments in the eu ets truly affected the carbon prices? Energy Policy 103:145-164. https://doi.org/10.1016/j.enpol.2017.01.008

Fang L, Yu H, Li L (2017) The effect of economic policy uncertainty on the long-term correlation between us stock and bond markets. Econ Model 66:139-145. https://doi.org/10.1016/j.econmod.2017.06.007

Fang L, Chen B, Yu H, Qian Y (2018) The importance of global economic policy uncertainty in predicting gold futures market volatility: a Garch-Midas approach. J Futur Mark 38(3):413-422. https://doi.org/10.1002/fut.21897

Fang L, Bouri E, Gupta R, Roubaud D (2019) Does global economic uncertainty matter for the volatility and hedging effectiveness of bitcoin? Int Rev Financ Anal 61:29-36. https://doi.org/10.1016/j.irfa.2018.12.010

Hansen PR, Lunde A, Nason JM (2011) The model confidence set. Econometrica 79(2):453-497. https://doi.org/10.3982/ ECTA5771

Hoque ME, Zaidi MAS (2019) The impacts of global economic policy uncertainty on stock market returns in regime switching environment: evidence from sectoral perspectives. Int J Finance Econ 24(2):991-1016. https://doi.org/10. 1002/ijfe.1702

Huang J, Luo Y, Peng Y (2019) Corporate financial asset holdings under economic policy uncertainty: precautionary saving or speculating? Int Rev Econ Finance. https://doi.org/10.1016/j.iref.2019.11.018

Kanamura T (2019) Supply-side perspective for carbon pricing. Quant Finance Econ 3(1):109. https://doi.org/10.3934/QFE. 2019.1.109

Kang B, Nikitopoulos CS, Prokopczuk M (2019) Economic determinants of oil futures volatility: a term structure perspective. Research paper series

Kautto N, Arasto A, Sijm J, Peck P (2012) Interaction of the eu ets and national climate policy instruments-impact on biomass use. Biomass Bioenerg 38:117-127. https://doi.org/10.1016/j.biombioe.2011.02.002 
Khan MK, Khan MI, Rehan M (2020) The relationship between energy consumption, economic growth and carbon dioxide emissions in Pakistan. Financ Innov 6(1):1-13

Koop G, Tole L (2013) Forecasting the European carbon market. J R Stat Soc A Stat Soc 176(3):723-741. https://doi.org/10. 1111/j.1467-985X.2012.01060.x

Kou G, Akdeniz ÖO, Dinçer H, Yüksel S (2021) Fintech investments in European banks: a hybrid it2 fuzzy multidimensional decision-making approach. Financ Innov 7(1):1-28

Lei L, Yu J, Wei Y, Lai X (2018) Forecasting volatility of Chinese stock market with economic policy uncertainty. J Manag Sci China 1(6):7. https://doi.org/10.1016/j.physa.2018.03.083

Li X (2019) Economic policy uncertainty and corporate cash policy: international evidence. J Account Public Policy 38(6):106694. https://doi.org/10.1080/00036846.2019.1613507

Li Y, Ma F, Zhang Y, Xiao Z (2019) Economic policy uncertainty and the Chinese stock market volatility: new evidence. Appl Econ 51 (49):5398-5410. https://doi.org/10.1080/00036846.2019.1613507

Liu HH, Chen YC (2013) A study on the volatility spillovers, long memory effects and interactions between carbon and energy markets: the impacts of extreme weather. Econ Model 35:840-855. https://doi.org/10.1016/j.econmod.2013. 08.007

Liu J, Cheng C, Yang X, Yan L, Lai Y (2019a) Analysis of the efficiency of Hong Kong Reits market based on Hurst exponent. Physica A 534:122035

Liu J, Huang Y, Chang CP (2019b) Leverage analysis of carbon market price fluctuation in china. J Clean Prod 245:118557

Mansanet-Bataller M, Pardo A (2009) Impacts of regulatory announcements on co2 prices. J Energy Mark 2(2):1-33. https://doi.org/10.21314/JEM.2009.019

Mansanet-Bataller M, Pardo A, Valor E (2007) Co2 prices, energy and weather. Energy J. https://doi.org/10.5547/ISSNO 195-6574-EJ-Vol28-No3-5

Milunovich G, Joyeux R (2010) Market efficiency and price discovery in the eu carbon futures market. Appl Financ Econ. https://ssrn.com/abstract=989272

Patton AJ (2011) Volatility forecast comparison using imperfect volatility proxies. J Econom 160(1):246-256

Venmans F (2015) Capital market response to emission allowance prices: a multivariate Garch approach. Environ Econ Policy Stud 17(4):577-620. https://doi.org/10.1007/s10018-015-0105-6

Wang Y, Chen CR, Huang YS (2014) Economic policy uncertainty and corporate investment: evidence from china. Pac Basin Financ J 26:227-243. https://doi.org/10.1016/j.pacfin.2013.12.008

Wang Y, Ma F, Wei Y, Wu C (2016) Forecasting realized volatility in a changing world: a dynamic model averaging approach. J Banking Finance 64:136-149. https://doi.org/10.1016/j.jbankfin.2015.12.010

Wei Y, Liu J, Lai X, Hu Y (2017) Which determinant is the most informative in forecasting crude oil market volatility: fundamental, speculation, or uncertainty? Energy Econ 68:141-150. https://doi.org/10.1016/.eneco.2017.09.016

Wen F, Yuan Y, Zhou WX (2019) Cross-shareholding networks and stock price synchronicity: evidence from china. arXiv preprint arXiv:190301655

Yan L, Xu F, Liu J, Teo KL, Lai M (2019) Stability strategies of demand-driven supply networks with transportation delay. Appl Math Model 76:109-121

Yin L (2016) Does oil price respond to macroeconomic uncertainty? New evidence. Empir Econ 51(3):921-938

Yu M, Song J (2018) Volatility forecasting: global economic policy uncertainty and regime switching. Physica A 511:316323. https://doi.org/10.1016/j.physa.2018.07.056

Yu H, Fang L, Sun W (2018) Forecasting performance of global economic policy uncertainty for volatility of Chinese stock market. Physica A 505:931-940. https://doi.org/10.1016/j.physa.2018.03.083

Zeitlberger AC, Brauneis A (2016) Modeling carbon spot and futures price returns with Garch and Markov switching Garch models. CEJOR 24(1):149-176. https://doi.org/10.1007/s10100-014-0340-0

Zha Q, Kou G, Zhang H, Liang H, Chen X, Li CC, Dong Y (2020) Opinion dynamics in finance and business: a literature review and research opportunities. Financ Innov 6(1):1-22

Zhang Y, Ma F, Shi B, Huang D (2018) Forecasting the prices of crude oil: an iterated combination approach. Energy Econ 70:472-483. https://doi.org/10.1016/j.eneco.2018.01.027

Zhang Y, Wei Y, Zhang Y, Jin D (2019) Forecasting oil price volatility: forecast combination versus shrinkage method. Energy Econ 80(MAY):423-433

Zhou K, Li Y (2019) Carbon finance and carbon market in china: progress and challenges. J Clean Prod 214:536-549

Zhu B, Chevallier J (2017) European carbon futures prices drivers during 2006-2012. In: Pricing and forecasting carbon markets, Springer, pp 13-31. https://doi.org/10.1007/978-3-319-57618-3_2

\section{Publisher's Note}

Springer Nature remains neutral with regard to jurisdictional claims in published maps and institutional affiliations. 